\title{
Young people and the problems of today
}

\author{
Hamid Ghodse
}

Director, Board of International Affairs, and Editor, International Psychiatry

\begin{abstract}
he foundations of adult health are established early in life, and at all stages of growing up - in infancy, childhood and adolescence - young people need healthy and supportive environments in which to grow to their full potential. At different stages of their lives they have different health and developmental needs but they are especially vulnerable during adolescence, when they are faced with a range of internal and external challenges, biological, psychological and social.
\end{abstract}

The vulnerability of children and adolescents to a variety of diseases and health problems is well known. This is so marked that childhood mortality is used as an indicator of a country's developmental stage and progress, one which often provides stark evidence of inequity in health and health services between different communities. Malnutrition and infectious diseases are particularly important causes of ill health early in life in many countries, and other factors play a greater role as children grow up. For example, substance misuse - by parents, peer groups, society in general and by the young people themselves - is a major threat to health. It encompasses the misuse of various psychoactive substances, both illicit and licit, including alcohol and tobacco (McArdle et al, 2002; Crome et al, 2004). It is a preventable condition and vividly illustrates the new challenges facing young people in the 2 I st century.

Young people live in a complex world that provides many of them with previously unimagined opportunities but also with new challenges. Because of globalisation, peer influences, which can be very powerful for the young, are no longer exerted solely at the local school and in the local neighbourhood but may originate thousands of miles away. New technologies and easier travel spread ideas, knowledge and behaviours quickly and efficiently. This may have huge benefits in terms of extending young people's experiences and understanding beyond their local communities but it also carries risks - for example, of exposure to aberrant behaviour and unsuitable role models - all at a time when young people are at their most impressionable and most likely to experiment with new things and to rebel against parental authority. At the same time, long-established sociocultural restraints on behaviour are becoming weaker.

Such factors make it more difficult to feel confident that children are growing up in the healthy environment that they need. Indeed, in many cases it is apparent that they are not and that, in consequence, both their mental health and their physical health are likely to be impaired (Baily, 2003). Substance misuse, for example, may directly increase the risk of accidental overdose and intoxication and, in the longer term, may lead to the development of drug dependence. Youngsters are also more likely to engage in unsafe sexual practices. These carry the risk of hepatitis, HIV and other sexually transmitted diseases, as well as of unintended pregnancy. Such immediate consequences can lead to a host of physical, mental and social problems, whose effects may be felt way into adulthood (Kumpulainen, 2000; Gue et al, 200 I; Department of Health, 2002; Crome et al, 2004).

These long-term consequences drive home the fact that risky adolescent behaviours should not be dismissed as passing phases of little importance. They require and deserve serious efforts at prevention and intervention, for the sake of both the individual young person and society as a whole. Psychiatrists in general, and child and adolescent specialists in particular, have an important role to play in this and are called on for advice on prevention and education, as well as intervention for individual patients. For all of the reasons outlined above, the demands upon these specialists are increasing and yet there are countries in the world with little or no access to child and adolescent psychiatry services and where adult mental health services are already stretched to the limit.

Nearly $40 \%$ of the world's population is composed of children and young people. They will form the backbone for development of their nations and we have a responsibility to do all we can to ensure that they grow up healthy and strong. Many communities will need particular help to develop the specialist skills that are required to nurture the next generation and to respond to their needs in an increasingly complex and challenging world.

\section{References}

Baily, S. (2003) Young offenders and mental health. Current Opinion in Psychiatry, 16, 581-59|.

Crome, I., Ghodse, H., Gilary, E., et al (eds) (2004) Young People and Substance Misuse. London: Gaskell.

Department of Health (2002) Prevalence of HIV and Hepatitis Infections in the United Kingdom. Annual Report of the Unlinked Anonymous Prevalence Monitoring Programme 2001. London: Department of Health.

Gue, J., Hawkins, J., Hill, K. G., et al (200I) Childhood and adolescent predictors of alcohol use and dependence in young adulthood. Journal of Studies on Alcohol, 62, 754-762.

Kumpulainen, K. (2000) Psychiatric symptoms and deviance in early adolescence predict heavy alcohol use 3 years later. Addiction, $95,1847-1857$

McArdle, P., O'Brian, G. \& Kolvin, I. (2002) European adolescent substance use: the role of family structure and gender. Addiction, 97, 329-336.
Because of
globalisation,
peer influences,
which can be
very powerful
for the young,
are no longer exerted solely at the local school and in the local

neighbourhood but may originate thousands of miles away.

Risky adolescent behaviours

should not be

dismissed as passing phases of little importance.

They require and deserve serious efforts at prevention and intervention, for the sake of both

the individual young person and society as a whole. 